(c) American Dairy Science Association, 2005.

\title{
Monitoring Indices of Cow Comfort in Free-Stall-Housed Dairy Herds*
}

\author{
N. B. Cook, T. B. Bennett, and K. V. Nordlund \\ School of Veterinary Medicine, University of Wisconsin-Madison, Madison 53706-1102
}

\begin{abstract}
Indices of cow comfort are used widely by consultants in the dairy industry, with a general understanding that they are representative of lying behavior. This study examines the influence of stall base type (sand or a geotextile mattress filled with rubber crumbs) and time of measurement on 4 indices of comfort collected at hourly intervals in 12 herds, aligned by morning and afternoon milking. Stall base type significantly influenced all indices of comfort. For example, the least squares mean (SE) cow comfort index (proportion of cows touching a stall that are lying down) was 0.76 (0.015) in herds with mattresses compared with 0.86 (0.015) in herds with sand stalls. Significant hourly variation was also identified suggesting that timing of measurement is important. None of the indices of cow comfort derived from the high-yielding group pen was associated with the mean 24-h lying time of 10 sentinel cows whose time budgets were known in each herd. However, the cow comfort index was associated with the herd mean 24-h stall standing time, with the strongest relationships occurring $2 \mathrm{~h}$ before the morning and afternoon milking, when stall base type did not significantly influence the association. When measured at these times, we recommend use of the stall standing index (proportion of cows touching a stall that are standing), with values greater than 0.20 being associated with abnormally long herd mean stall standing times greater than $2 \mathrm{~h} / \mathrm{d}$.
\end{abstract}

(Key words: comfort index, stall use, lameness)

Abbreviation key: CCI = cow comfort index or quotient, CCI/SSI cow $_{\text {c }}$ cow comfort index/stall standing index measured for the individual cows, $\mathbf{C C I} / \mathbf{S S I}_{\text {pen }}=$ cow comfort index/stall standing index measured for the pen, MAT = geotextile-covered mattresses filled with rubber crumbs for free stalls, SAND = sand-bedded free stall, SPI = stall perching index, $\mathbf{S S I}=$ stall standing index, $\mathbf{S U I}=$ stall use index.

Received March 21, 2005.

Accepted July 20, 2005.

Corresponding author: Nigel B. Cook; e-mail: nbcook@wisc.edu.

*This study was funded by grants obtained from the UW-SVM, Food Animal Fund, Land O'Lakes, Inc., and other Supporters of the UW Cow Comfort and Well-Being Consortium.

\section{INTRODUCTION}

Indices of cow comfort, such as the cow comfort index (CCI) or cow comfort quotient, defined here as the proportion of cows touching a stall that are lying down, were first described almost a decade ago, and are used widely by dairy consultants to help them assess a dairy cow facility (Nelson, 1996). It is surprising, therefore, to realize that few studies have been published that investigate the use of CCI in commercial dairy herds. Despite widespread agreement that the CCI and equivalent indices are representative of good stall use by dairy cows, and therefore a reflection of daily lying behavior, no study has attempted to show just how well CCI or any other index of comfort is associated with daily lying behavior. Indeed, until recently, there were few guidelines on the appropriate timing of their measurement during the day.

Several studies have shown a diurnal pattern to feeding and lying activity in free-stall housing (Miller and Wood-Gush, 1991; Overton et al., 2002; DeVries and von Keyserlingk, 2005). One study tracked stall-use activity in a sand stall pen in a Californian dairy over an 8-d period (Overton et al., 2002, 2003). Peak lying activity was observed $1 \mathrm{~h}$ after return of the cows to the pen from the morning milking. This time coincided with the maximum CCI (Overton et al., 2003) and this was recommended as an optimal time to capture the best stall use in the herd. A target CCI of greater than 0.85 was suggested. In addition, the same researchers suggested the use of an alternative index known as the stall use index (SUI), which is defined as the proportion of cows that are in the pen, not feeding, and that are lying down in the stalls (Overton et al., 2003). The diurnal variation in this index appeared to be greater than in the CCI, and a target of greater than 0.75 was recommended when measured at a similar time $(1 \mathrm{~h}$ after return from milking).

Variation in indices of comfort among herds has been documented infrequently. A study of 15 free-stall herds in Wisconsin determined an index of cow comfort equivalent to the reciprocal of the CCI, referred to here as the stall standing index (SSI, where SSI $=1$ - CCI), which measured the proportion of cows touching a stall that were standing with all 4 feet on the stall platform or perching with the front 2 feet in the stall and the rear 
2 feet in the alley (Cook, 2002). The SSI was collected 1 to $2 \mathrm{~h}$ before morning or afternoon milkings in both summer and winter and ranged from 6 to $35 \%$ between herds and seasons, suggesting a wide variation worthy of investigation.

The herd mean stall lying time and stall standing time derived from 10 sentinel cows in the high-yielding group pen in each of 12 herds obtained from a previous study (Cook et al., 2004), which evaluated individual cow time budgets, provided an opportunity to investigate variation in indices of cow comfort in herds with stall surfaces covered with geotextile mattresses filled with rubber crumbs (MAT), or stalls bedded with loose, deep sand (SAND). Specifically, there were 2 main aims for the current study. Firstly, to determine how different indices of comfort vary throughout the day in herds with different stall base types (MAT or SAND) and to identify periods of peak stall use. Secondly, the study aimed to determine how these indices are associated with the herd mean lying and standing times obtained from the 10 sentinel cows in each pen. The association was tested for 1 database with indices derived from the 10 sentinel cows, to test whether there was any association between index and behavior at a cow level, and for a second database in which the indices were derived from all of the cows in the high-yielding group pen in each herd, to test whether the association exists at the pen level. If there were such an association between indices and cow behavior, the timing of the optimal association would serve as a recommendation for the measurement of indices of comfort in other herds. The indices previously mentioned were calculated (CCI, SSI, SUI), and in addition, a third index was measured for the pen level data, referred to as the stall perching index (SPI), defined as the proportion of cows touching a stall that were standing with only the front 2 feet in the stall and the rear feet in the alley.

\section{MATERIALS AND METHODS}

\section{Herd Selection and Data Collection}

Twelve herds were used for the study. Selection criteria and background information for the herds have been documented in a previous publication on time budgets of individual cows that had been monitored for a 24-h period (Cook et al., 2004). The herds were between 150 and 450 cows with drive-through TMR feeding, a highyielding group pen size of between 70 and 100 cows, and a stocking density not exceeding $125 \%$ (i.e., 125 cows per 100 stalls). Number of rows of stalls in the pen on each farm (2 or 3 row) and milking frequency (2 or 3 times/d) on each farm were equally distributed between 6 herds using sand-bedded stalls (SAND) and 6 herds using a rubber crumb-filled geotextile mattress
(MAT). Four Sony miniDV video cameras (DCRTRV900; Sony Corp., New York, NY), mounted in the adjacent pen across the central feed alley and arranged to capture video of the entire high-yielding group pen in 4 overlapping zones, recorded $1 \mathrm{~s}$ of video every $30 \mathrm{~s}$. A single 24 -h period of activity was captured, during which there were no interruptions for breeding, injections, or other management tasks. Lights over the pen were left on during the night so that filming could continue for the full $24 \mathrm{~h}$. Although not ideal, the herds studied were commercial dairy herds and a short period of all-day lighting has been used in other studies to facilitate recording without apparent major effects on cow behavior (Metz, 1985; Tucker et al., 2003; Cook et al., 2004). Filming was performed between April 2002 and May 2003 and avoiding the period typically associated with heat stress in Wisconsin (between July and October).

Cows selected for individual tracking were identified at least $1 \mathrm{~h}$ before the start of filming. Cows that were notably much smaller or larger than the pen average, cows with overgrown feet, and cows that were obviously severely lame (walking with an arched back, almost unable to bear weight on the affected limb; Cook, 2003) were not chosen. Severely lame cows represented only $3.2 \%$ of the population under study in the MAT herds and $0.7 \%$ of the population in SAND herds.

\section{Calculation of Indices}

Using a Panasonic AG-DV2000P MiniDV editing player and Panasonic CT-2089VYD high-definition color monitor (Matsushita Electric Corporation of America, Los Angeles, CA), the videotapes were analyzed hourly for each herd to create 2 databases. The first calculated the indices of comfort from the 10 sentinel cows only, and the second determined the indices from all of the cows in the pen, referred to subsequently using the subscript "cow" or "pen" after the index abbreviation to indicate the source of the data $\left(\mathbf{C C I}_{\text {cow }}\right.$, $\mathbf{C C I}_{\text {pen }}, \mathbf{S S I}_{\text {cow }}$, and $\mathbf{S S I}_{\text {pen }}$ ). At each hour, the number of cows that were lying down in a stall, standing in a stall with all 4 feet, standing in a stall with the rear 2 feet in the alley (perching), and standing in the alley drinking and feeding were recorded. If it was not clear whether a particular cow was perching or standing with all 4 feet in the stall, a default value was used, which removed the observation from the analysis at that time point. Perching data were not available for the individual cow database. For each database and for each hour, 4 indices of cow comfort were calculated, namely CCI, SSI, SPI, and SUI. For the purpose of statistical analyses, CCI and SSI were the same, as one is the reciprocal of the other. 
Times within a few hours before or after the morning and afternoon milkings have been suggested as the most appropriate times to measure indices of cow comfort. Therefore, to facilitate across-herd comparison for each database, the start time of the morning milking, when the cows started to leave the pen (h 0 ) was used as a reference point to align the hourly data for each farm for $5 \mathrm{~h}$ before and $6 \mathrm{~h}$ after $\mathrm{h} 0$. Across herds, $\mathrm{h}$ 0 ranged from 0400 to $0720 \mathrm{~h}$ Beginning with $\mathrm{h} 6$, the data were realigned across herds for $5 \mathrm{~h}$ before and 6 $\mathrm{h}$ after the start time of the afternoon milking, when the cows started to leave the pen (h 11). Across all herds, h 11 ranged from 1400 to $1854 \mathrm{~h}$. The aim of this synchronization of data across farms was to make effective comparisons relative to starting times for each milking.

The herd means for 24-h stall lying time and stall standing time of the 10 sentinel cows that had been selected from each herd were used to test the association between stall use behavior and indices of comfort. The associations were tested for each index at each hour for indices derived from the 10 sentinel cows themselves, to justify further examination of the data at the pen level, and for the indices derived from the whole pen, to identify the most appropriate times for measurement.

\section{Statistical Analyses}

Differences in least squares means for herd size, lameness prevalence in the high group pen, high group pen stocking density (cows per stall), mean 24-h times lying and standing in the stall for the 10 sentinel cows in each herd, stall width, and horizontal and vertical location of the neck rail in the stall (included as factors which might influence stall standing behavior), were tested using 1-way ANOVA between MAT and SAND herds in SAS (SAS Institute, 1999). Data were transformed where appropriate to ensure an approximate normal distribution.

Differences in the indices of cow comfort between SAND and MAT herds derived from all of the cows in each pen were modeled over time in PROC MIXED in SAS (SAS Institute, 1999) with farm, stall base type, and hour in the class statement, and a random statement for stall base within farm. Two repeated measures covariance structures were tested (compound symmetry and first-order autoregressive, AR-1), and the optimal model chosen using assessment of the magnitude of Akaike's information criterion. A level of $P<0.05$ was used to determine significance for the effects of stall base (1 degree of freedom), hour (22 degrees of freedom), and the interaction between stall base and hour (22 degrees of freedom).
The associations between the indices of cow comfort recorded at each hour for each herd and the mean herd 24-h lying and stall standing times derived from the 10 sentinel cows in each herd were examined using PROC REG in SAS (SAS Institute, 1999). This analysis was first performed for the database derived from only the 10 sentinel cows, and then on the database derived from the whole pen. Because of the repetitive nature of the comparisons and to account for multiple testing of the same hypotheses, a Bonferroni correction was made to the $P$-values by multiplying them by the number of comparisons made $(n=22)$. This adjustment was used to reduce the chances of making an erroneous conclusion (Dohoo et al., 2003); the strongest associations were determined based on the corrected threshold level of significance $(P<0.05)$ and the value of the adjusted $R^{2}$.

Having selected likely important relationships between indices of cow comfort and cow activity at each hourly comparison, PROC GLM (SAS Institute, 1999) was used to examine the impact of fixed effects of stall base type, herd milking frequency, number of rows of stalls in the pen, and their interactions on the relationship. Significance was evaluated using Type III sum of squares and $P<0.05$. Nonsignificant effects were removed from the model by the process of backwards elimination.

\section{RESULTS}

\section{Herd Background Information}

Background data for the herds relevant to this study are presented in Table 1 by stall base type. Other background information has previously been presented for the study herds and for the cows selected for monitoring of time budgets (Cook et al., 2004). No significant differences were observed between stall base types for herd size and high group pen stocking density. There was no significant difference between SAND and MAT herds in mean (range) vertical height of the neck rail above the stall surface [1.19 (1.12 to 1.25$)$ vs. $1.16 \mathrm{~m}$ (1.13 to 1.21)], mean (range) horizontal location of the neck rail in relation to the rear curb [1.64 (1.55 to 1.75$)$ vs. 1.64 $\mathrm{m}$ (1.57 to 1.78$)$ ], and mean stall width (1.15 vs. $1.16 \mathrm{~m}$ ).

A highly significant difference in high group pen lameness prevalence was seen $(P<0.001)$, with the prevalence in MAT herds being more than 3 times that observed in SAND herds. The mean 24-h lying and stall standing times for the sentinel cows by stall base type are shown in Table 1 and presented graphically in Figure 1 by herd. The mean (SE) time spent standing in the stall was significantly higher in the MAT herds at $3.44(0.36) \mathrm{h}$ compared with $1.83(0.36) \mathrm{h}$ in SAND 
Table 1. Least squares means and SE herd size, pen stocking rate, lameness prevalence and standing and lying behavior of 10 sentinel cows in 6 herds using mattress stalls (MAT) and 6 herds using sand stalls (SAND).

\begin{tabular}{lcccc}
\hline & MAT & SAND & SE & $P$ \\
\hline Herd size (no. of cows) & 304.7 & 297.7 & 30.2 & 0.87 \\
Stocking rate (high pen, \%) $_{\text {Lameness prevalence }}$ (high pen, \%) & 107.8 & 108.0 & 5.0 & 0.98 \\
Mean 24-h time lying down (h) & 29.3 & 8.2 & 2.2 & $<0.001$ \\
Mean 24-h time standing in the stall (h) & 11.66 & 12.01 & 0.51 & 0.64 \\
\hline
\end{tabular}

${ }^{1}$ Clinical lameness included cows that had locomotion scores of 3 and 4 on a scale of 1 to 4 , where $1=$ nonlame, 2 = slightly lame, 3 = moderately lame, and $4=$ severely lame.

herds, but there was no significant difference in mean lying time.

\section{Effect of Stall Base and Hour on Indices of Cow Comfort}

The autoregressive (AR-1) covariance structure provided the optimal model for each of the indices, and the results from this model are quoted. There was a significant hour and stall base effect for all of the indices, but the interaction between base and hour was not significant (Table 2). The effects of hours before and after the start of morning milking (h 0 ) and afternoon milking (h 11) on the indices of cow comfort for all herds grouped by stall base type are shown in Figure 2 .

Across the 24 -h period, the $\mathrm{CCI}_{\text {pen }}$ least squares mean (SE) for MAT herds was 0.76 (0.015), compared with $0.86(0.015)$ for SAND herds. The maximum value was obtained at $\mathrm{h} 4$ after the start of morning milking in MAT herds (0.85) and at $\mathrm{h} 3$ for SAND herds (0.93; Figure 2). The SSI $_{\text {pen }}$ followed a similar but inverted pattern, with a least squares mean of $0.14(0.015)$ for SAND herds and $0.24(0.015)$ for MAT herds. The least squares mean $\mathrm{SUI}_{\text {pen }}$ was higher for SAND herds (0.76) than MAT herds (0.70) with maximum values being obtained at h 2 and h 4 after the start of morning

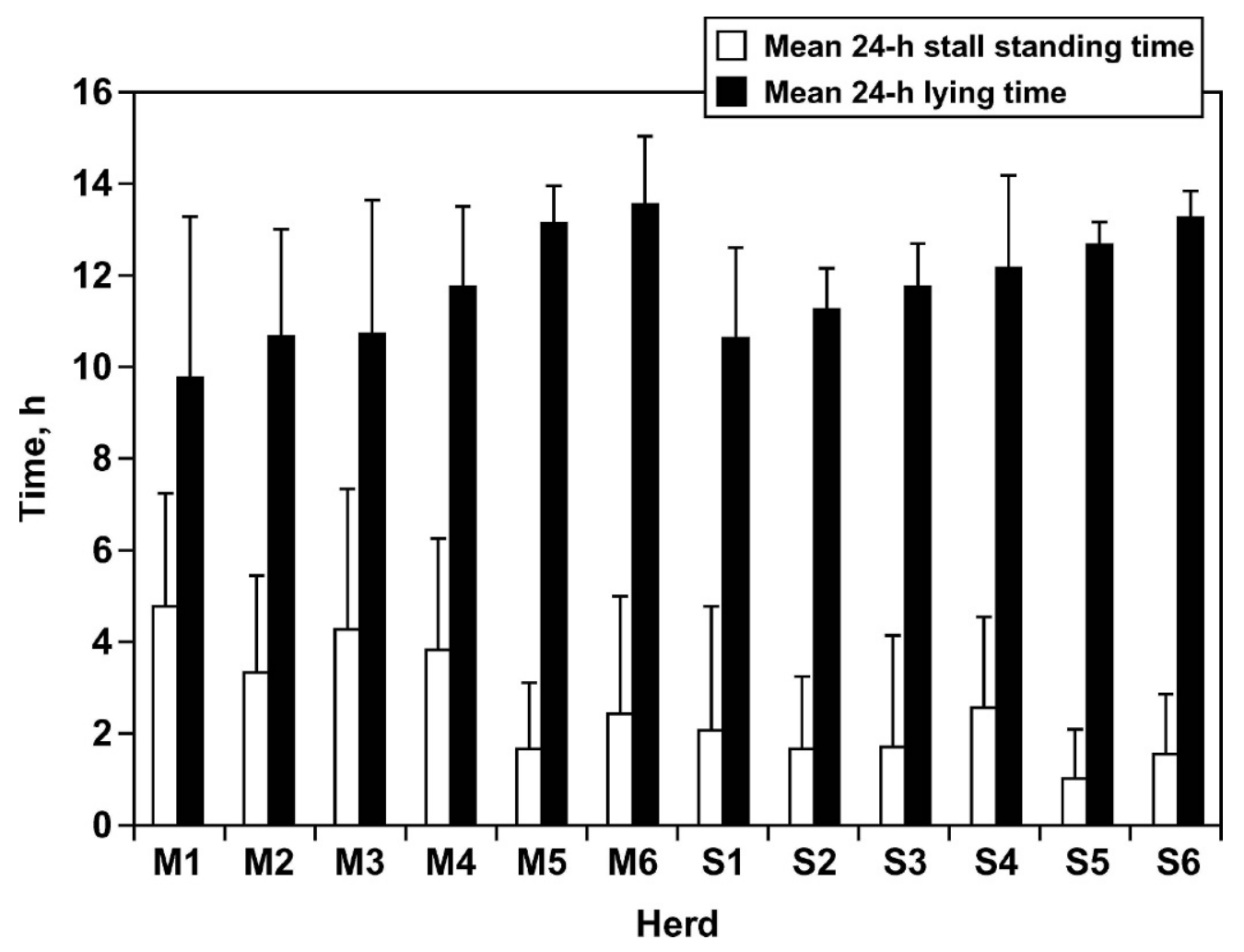

Figure 1. Variation in herd mean 24-h lying time and 24-h stall standing time (bars indicate 1 SD) for 10 cows in each of 12 herds, 6 with mattress stalls (M1 to M6) and 6 with sand stalls (S1 to S6). 
Table 2. Results of the first-order autoregressive repeated measures model examining the effect of hour and stall base type (sand or mattress, SAND or MAT, respectively) on the indices of cow comfort derived from the high-yielding group pen with least squares means and SE for SAND and MAT herds.

\begin{tabular}{lllllll}
\hline & & & & \multicolumn{3}{c}{$P$-values } \\
\cline { 5 - 7 } Comfort index & MAT & SAND & SE & Stall base & Hour & $\begin{array}{l}\text { Stall base } \\
\times \text { Hour }\end{array}$ \\
\hline Cow comfort index & 0.761 & 0.858 & 0.015 & 0.001 & $<0.001$ & 0.643 \\
Stall standing index & 0.239 & 0.142 & 0.015 & 0.001 & $<0.001$ & 0.643 \\
Stall perching index & 0.094 & 0.126 & 0.008 & 0.023 & $<0.001$ & 0.866 \\
Stall use index & 0.696 & 0.763 & 0.011 & 0.002 & $<0.001$ & 0.549 \\
\hline
\end{tabular}

milking in SAND and MAT herds, respectively. The least squares mean (SE) $\mathrm{SPI}_{\text {pen }}$ was higher in SAND herds at 0.13 (0.008) compared with MAT herds at 0.09 (0.008), with minimum values being obtained at $1 \mathrm{~h}$ after the morning milking for both groups of herds.

\section{Association between Comfort Indices and Herd Mean 24-h Standing and Lying Times}

Indices derived from 10 sentinel cows. Using linear regression analysis, none of the indices derived from the 10 sentinel cows were significantly associated with herd mean 24-h lying time derived from the same cows at any hour measured $(P>0.33)$. However, a significant association was found between CCI/SSI $\mathrm{Sow}_{\text {co }}$ and mean 24-h time standing in the stall when captured at $\mathrm{h} 2$ after the morning milking (adjusted $\mathrm{R}^{2}=0.69, P<$ 0.001 ), with several other time points trending toward significance, including $2 \mathrm{~h}$ before the afternoon milking. These associations are shown for CCI/SSI $\mathrm{Sow}_{\text {in }}$ Table 3 . There was also a significant association with $\mathrm{SUI}_{\text {cow }}$ when captured at h 2 after the morning milking (adjusted $\mathrm{R}^{2}=0.70, P<0.001$ ). This finding suggested that there might be an association between stall standing
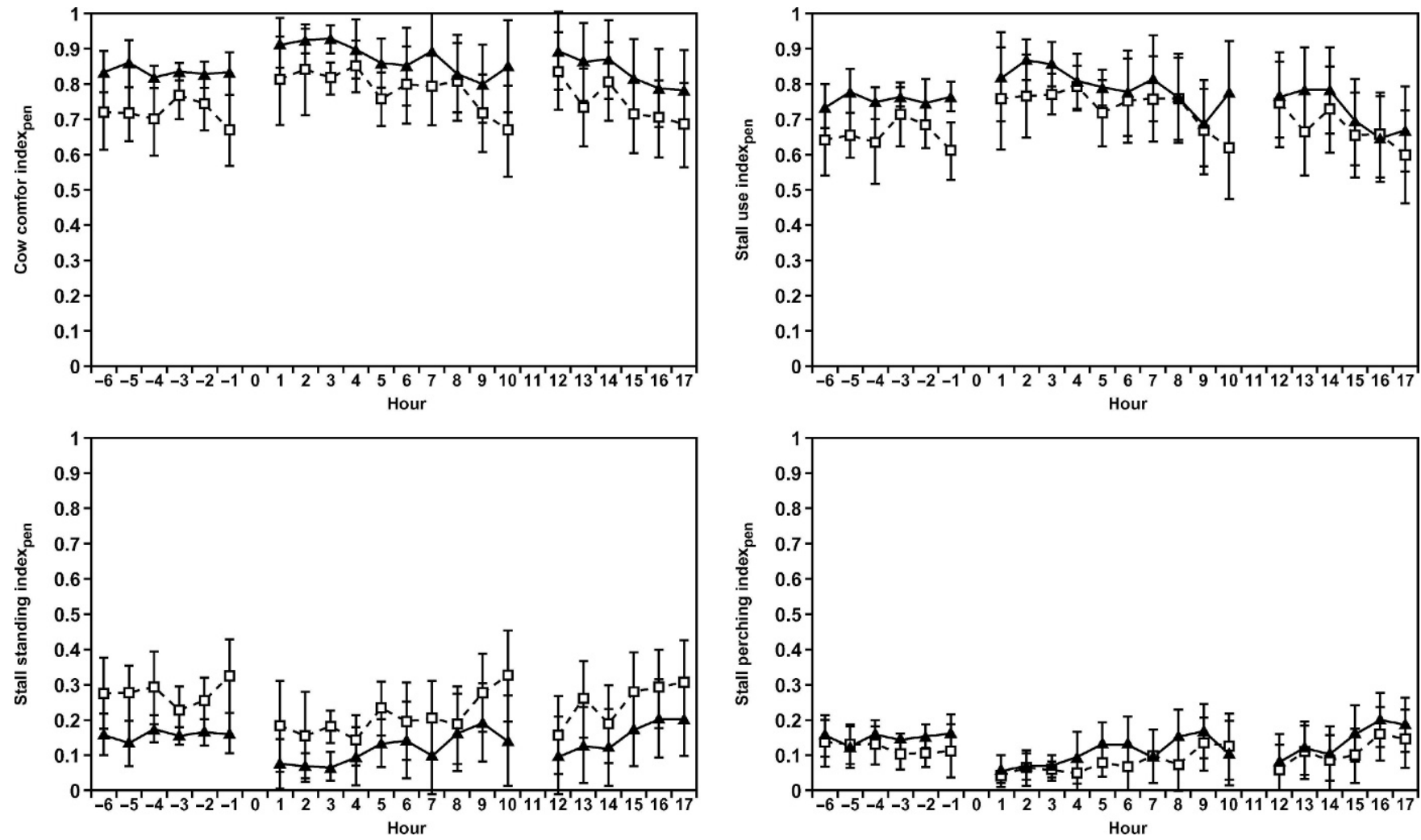

Figure 2. The effect of hour and stall base type on the least squares mean (bars indicate 1 SD) cow comfort index (CCI), stall use index (SUI), stall standing index (SSI), and stall perching index (SPI) derived from the high-yielding group pen for sand-bedded free stall herds $(\boldsymbol{\Lambda}, \mathrm{n}=6)$ and mattress-bedded herds $(\square, \mathrm{n}=6)$, aligned by start of morning milking (h 0 ) and start of afternoon milking (h 11). 
Table 3. Linear regression analysis adjusted R2 and Bonferroniadjusted $P$-values for cow comfort index/stall standing index derived from 10 cows in the pen (CCI/SSI cow $\left._{\text {ow }}\right)$ by hours before and after $\mathrm{h} 0$ compared with the herd mean 24 -h time standing in the stall and herd mean 24-h lying time of the 10 cows per herd.

\begin{tabular}{|c|c|c|c|c|}
\hline \multirow[b]{2}{*}{ Hour $^{1}$} & \multicolumn{2}{|c|}{$\begin{array}{l}\text { Herd mean stall } \\
\text { standing time }\end{array}$} & \multicolumn{2}{|c|}{$\begin{array}{l}\text { Herd mean } \\
\text { lying time }\end{array}$} \\
\hline & Adjusted-R ${ }^{2}$ & $P^{*}$ & Adjusted-R ${ }^{2}$ & $P^{*}$ \\
\hline-6 & 0.15 & NS & 0.03 & NS \\
\hline-5 & 0.20 & NS & 0.23 & NS \\
\hline-4 & -0.05 & NS & 0.02 & NS \\
\hline-3 & 0.07 & NS & 0.40 & 0.352 \\
\hline-2 & 0.36 & 0.506 & 0.29 & 0.902 \\
\hline-1 & 0.53 & 0.528 & 0.44 & 0.968 \\
\hline \multicolumn{5}{|c|}{0.02} \\
\hline 1 & 0.16 & NS & -0.11 & NS \\
\hline 2 & 0.69 & $<0.001$ & 0.29 & 0.924 \\
\hline 3 & 0.08 & NS & 0.25 & NS \\
\hline 4 & -0.01 & NS & -0.06 & NS \\
\hline 5 & -0.04 & NS & -0.09 & NS \\
\hline 6 & -0.06 & NS & -0.10 & NS \\
\hline 7 & -0.05 & NS & -0.08 & NS \\
\hline 8 & 0.15 & NS & 0.02 & NS \\
\hline 9 & 0.55 & 0.09 & 0.16 & NS \\
\hline 10 & 0.42 & 0.77 & -0.05 & NS \\
\hline \multicolumn{5}{|l|}{11} \\
\hline 12 & 0.17 & NS & -0.06 & NS \\
\hline 13 & 0.15 & NS & -0.10 & NS \\
\hline 14 & 0.09 & NS & 0.20 & NS \\
\hline 15 & -0.08 & NS & 0.03 & NS \\
\hline 16 & 0.43 & 0.264 & 0.21 & NS \\
\hline 17 & 0.51 & 0.176 & 0.22 & NS \\
\hline
\end{tabular}

${ }^{1}$ Hour relative to $\mathrm{h} 0$, when cows left the pen for morning milking; Hour 11 = time when cows left the pen for afternoon milking.

*Bonferroni-adjusted $P$-value where NS is nonsignificant at 1.0 or greater.

behavior and indices of comfort worthy of further investigation at the level of the whole pen.

Indices derived from all cows in the pen. There was no significant association between any of the indices derived from the whole pen and the mean 24-h lying time from the 10 sentinel cows in each herd at any hour measured $(P>0.44)$. In addition, at any hour of measurement, there was no significant association of

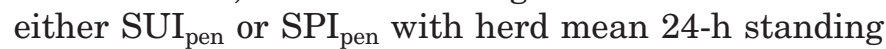
time. However, significant associations were found be-

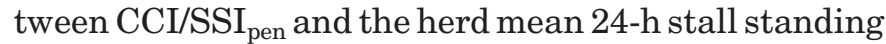
time at 5 and $2 \mathrm{~h}$ before the start of the morning milking and at $2 \mathrm{~h}$ before and $2 \mathrm{~h}$ after the start of the afternoon milking $(P<0.001)$, with the combination of adjusted $R^{2}$ and $P$-value being most favorable for the measurement taken at $2 \mathrm{~h}$ before the afternoon milking, at $\mathrm{h} 9$ (Table 4).

The relationship between CCI/SSI pen $_{\text {at }} 5$ and $2 \mathrm{~h}$ before the morning milking and at $2 \mathrm{~h}$ before and $2 \mathrm{~h}$ after the afternoon milking, and the herd mean 24-h standing time from the 10 sentinel cows was further examined in PROC GLM (SAS Institute, 1999), where the effects of stall base type, number of rows of stalls, milking frequency, and their interactions with the hourly measured index of comfort were considered as covariates.

Neither milking frequency, number of rows of stalls, or stall base alone were significant factors in any of the associations $(P>0.3)$. The CCI/SSI $\mathrm{Sen}_{\text {measured at each }}$ of the periods was significantly associated with the mean 24-h time standing in the stalls at 5 and $2 \mathrm{~h}$ before the morning milking ( $P=0.021$ and 0.014 , respectively) and $2 \mathrm{~h}$ before the afternoon milking $(P<0.001)$, but not at $2 \mathrm{~h}$ after the afternoon milking $(P=0.274)$. However, at $5 \mathrm{~h}$ before the morning milking, there was a significant interaction between stall base and index $(P=$ 0.033 ), making interpretation of this index when measured at this time difficult between herds with different stall base types. Thus, the timing of measurement which best explained the association between the CCI/ SSI $_{\text {pen }}$ and the mean 24-h time standing in the stalls appeared to be $2 \mathrm{~h}$ before the morning or afternoon milking. The relationships are shown graphically along with regression equations in Figures 3 and 4.

\section{DISCUSSION}

The synchronized pattern of resting activity in the herds in the current study reflected that reported previously (Overton et al., 2002), in which maximum lying activity during the day typically occurred in the first few hours after return of the cows to the pen from the morning milking, with a secondary peak after the return from the afternoon milking. The effect of night milking was not shown in this data set owing to the difficulties of synchronizing the time points relative to milking across herds. There was a significant effect of hour of determination on all of the indices of comfort and it is clear that the timing of their measurement is an important factor influencing their magnitude.

The CCI is the most commonly used index, and it has been proposed that a value greater than 0.85 is a realistic goal (Nelson, 1996). Although Nelson (1996) did not specify a time for measurement, Overton et al., (2002) suggested capturing the best possible estimate at $1 \mathrm{~h}$ after return to the pen from the morning milking. The pen data in the current study show that the peak CCI was likely slightly later than $1 \mathrm{~h}$ after return from milking, although time was measured from the start rather than the end of milking (Figure 2). However, this timing does not reflect the magnitude of the average index of comfort obtained throughout the rest of the day, nor was this time significantly associated with the time budgets of individual cows within the pen. Indices more typical of the daily average may be obtained a few hours before or a few hours after the morn- 
Table 4. Linear regression analysis adjusted $\mathrm{R}^{2}$ and Bonferroni-adjusted $P$-value for indices of cow comfort derived from the high-yielding group pen by hours before and after $\mathrm{h} 0$ compared with the herd mean 24$\mathrm{h}$ time standing in the stall of 10 sentinel cows per herd.

\begin{tabular}{|c|c|c|c|c|c|c|}
\hline \multirow[b]{2}{*}{ Hour $^{1}$} & \multicolumn{2}{|c|}{$\begin{array}{l}\text { Cow comfort index/stall } \\
\text { standing index }\end{array}$} & \multicolumn{2}{|c|}{ Stall use index } & \multicolumn{2}{|c|}{ Stall perching index } \\
\hline & Adjusted $\mathrm{R}^{2}$ & $P^{*}$ & Adjusted $\mathrm{R}^{2}$ & $P^{*}$ & Adjusted $\mathrm{R}^{2}$ & $P^{*}$ \\
\hline-6 & 0.29 & 0.924 & 0.09 & NS & -0.09 & NS \\
\hline-5 & 0.66 & $<0.001$ & 0.58 & 0.056 & 0.09 & NS \\
\hline-4 & 0.28 & 0.990 & 0.20 & NS & 0.02 & NS \\
\hline-3 & 0.21 & NS & -0.03 & NS & -0.07 & NS \\
\hline-2 & 0.77 & $<0.001$ & 0.27 & NS & -0.09 & NS \\
\hline \multirow{2}{*}{\multicolumn{7}{|c|}{-0.04}} \\
\hline & & & & & & \\
\hline 1 & 0.15 & NS & 0.00 & NS & -0.02 & NS \\
\hline 2 & 0.25 & NS & 0.16 & NS & -0.08 & NS \\
\hline 3 & 0.52 & 0.11 & 0.27 & NS & -0.04 & NS \\
\hline 4 & 0.08 & NS & -0.09 & $\mathrm{NS}$ & -0.07 & NS \\
\hline 5 & 0.53 & 0.11 & 0.32 & 0.726 & -0.06 & NS \\
\hline 6 & -0.02 & NS & -0.08 & NS & -0.00 & NS \\
\hline 7 & 0.33 & 0.660 & -0.02 & NS & -0.09 & NS \\
\hline 8 & -0.02 & NS & -0.07 & NS & 0.39 & 0.374 \\
\hline 9 & 0.91 & $<0.001$ & 0.17 & NS & -0.08 & NS \\
\hline 10 & 0.67 & 0.176 & 0.39 & NS & -0.02 & NS \\
\hline \multicolumn{7}{|l|}{11} \\
\hline 12 & 0.47 & 0.198 & -0.05 & NS & -0.09 & NS \\
\hline 13 & 0.83 & $<0.001$ & 0.42 & 0.301 & -0.10 & NS \\
\hline 14 & 0.35 & 0.572 & 0.04 & NS & -0.10 & NS \\
\hline 15 & 0.53 & 0.11 & 0.11 & NS & -0.10 & NS \\
\hline 16 & 0.32 & 0.682 & -0.06 & NS & -0.10 & NS \\
\hline 17 & 0.44 & 0.352 & 0.19 & NS & -0.10 & NS \\
\hline
\end{tabular}

${ }^{1}$ Hour relative to $\mathrm{h} 0$, when cows left the pen for morning milking; Hour $11=$ time when cows left the pen for afternoon milking.

*Bonferroni-adjusted $P$-value where NS is nonsignificant at 1.0 or greater

ing or afternoon milking, and their assessment at these times may be more appropriate.

The differences between herds with different stall base types are also of importance, as a significant stall base effect on all 4 indices of cow comfort was demonstrated. For MAT herds, on average, the 0.85 goal for CCI would be met $4 \mathrm{~h}$ after the morning milking, but would have been below the standard for the rest of the day, whereas SAND herds would exceed the goal for most of the day. Thus, if we were to measure an index of comfort in a herd, we would need to be aware of the effect of timing of measurement and the influence of stall base type, rather than using one simple threshold across different farms and different times of the day.

Measurements of the CCI or SUI have been taken with a view to them reflecting the resting behavior of the group under examination, with the consensus that high scores reflect improved lying time. If this is the case, then the most appropriate timing of measurement of the index should be that which predicts daily lying time most accurately. This approach to timing would seem preferable to the option of trying to capture the highest value achieved during the day. Knowledge of the standing and resting activity of 10 sentinel cows in each pen was therefore of great use in determining this predictive ability. This comparison assumes that comfort indices derived from the cows are related to their behavior, and that the activity of the individuals chosen reflects that of the average of the pen. Although the selection of cows for tracking of individual time budgets was not completely random, we did not select against groups that would have comprised the majority of cows in the pen. Severely lame cows were not included, but this group of cows represented a very small proportion of the total study population. None of the comfort indices derived from the 10 cows in each herd was significantly related to the herd mean 24-h lying time. However, the significant association between $\mathrm{CCI}_{\text {cow }}$ and $\mathrm{SUI}_{\text {cow }}$ measured at $2 \mathrm{~h}$ after the morning milking and the herd mean 24-h time spent standing in the stalls, suggested that it was worth pursuing the relationship between indices of comfort and herd mean stall standing and lying times on a whole-pen basis.

None of the indices of cow comfort derived from the whole pen was associated with herd mean 24-h lying

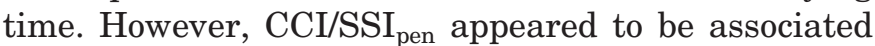
with mean 24-h stall standing activity at certain times of the day. Associations at $5 \mathrm{~h}$ before and $2 \mathrm{~h}$ before $\mathrm{h}$ 0 (when cows left the pen for the morning milking), and $2 \mathrm{~h}$ before and after $\mathrm{h} 11$ (when cows left the pen for 


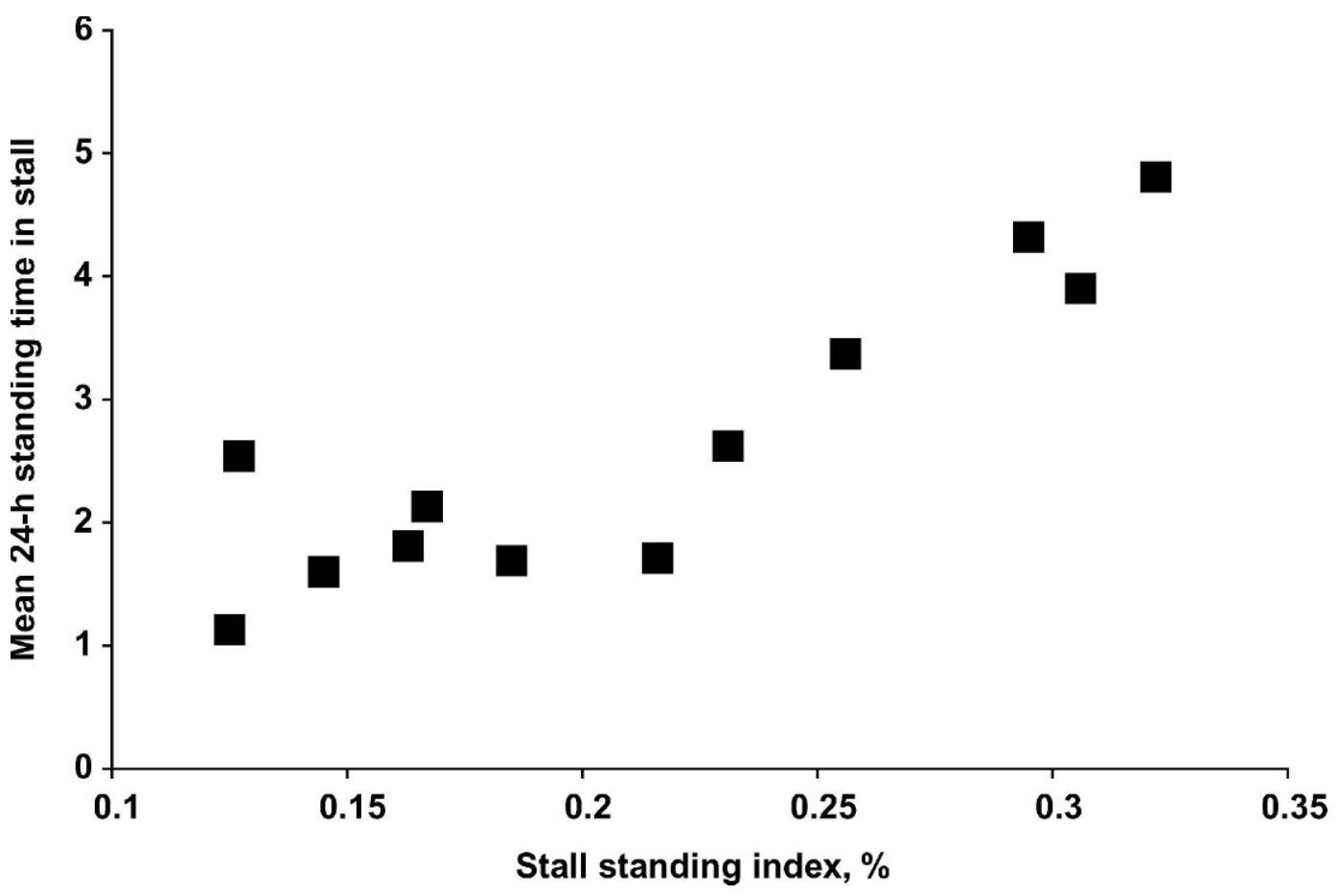

Figure 3. The relationship between stall standing index derived from the high-yielding group pen ( $\left.\mathrm{SSI}_{\text {pen }}\right)$ measured at $2 \mathrm{~h}$ before the morning milking $(\mathrm{h}-2)$ and mean 24 -h time spent standing in the stall for each of 12 herds. The relationship is explained by the equation $\mathrm{y}=15.09 \mathrm{x}-0.56 ; \mathrm{R}^{2}=0.77$.

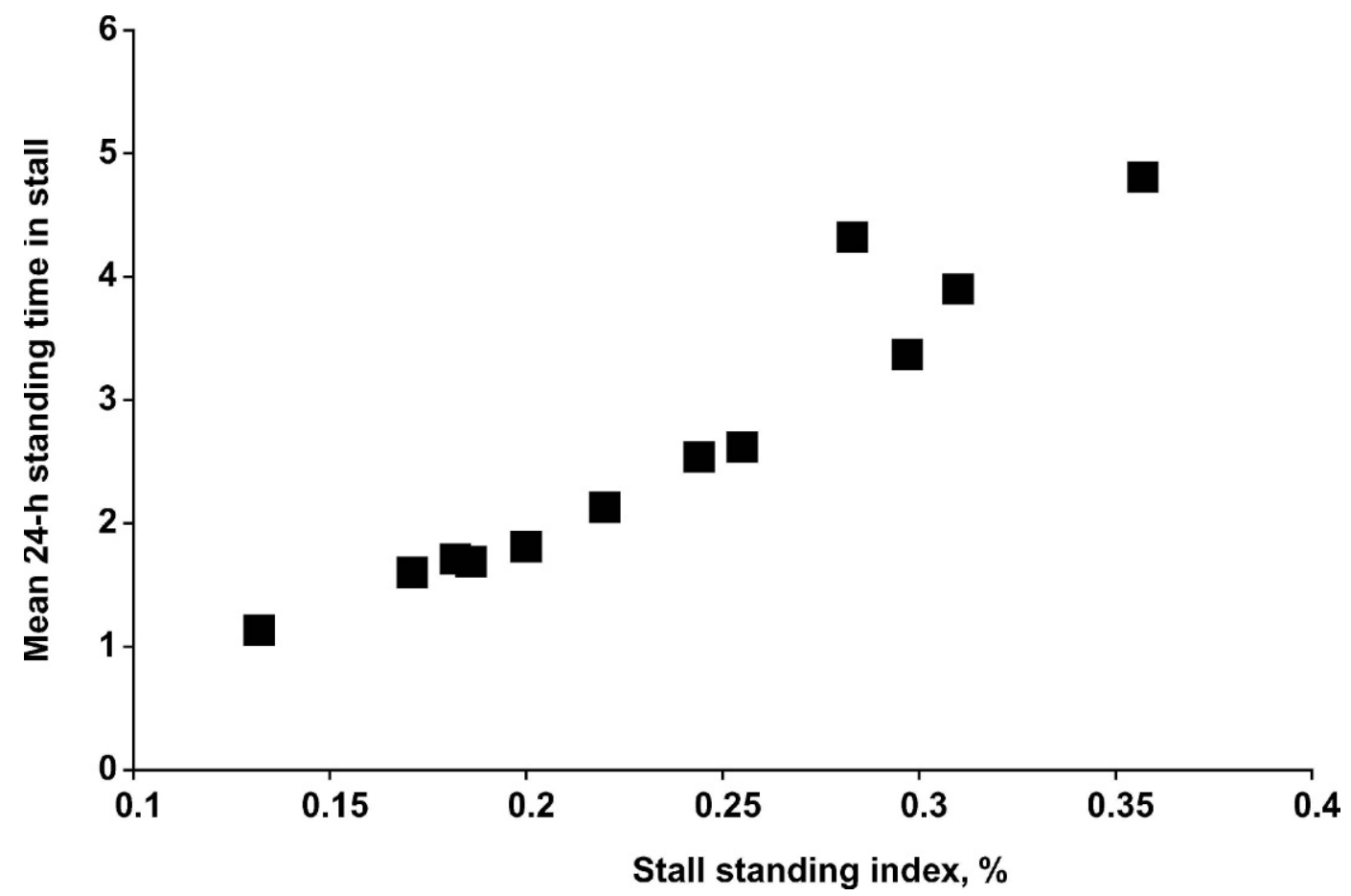

Figure 4. The relationship between stall standing index derived from the high-yielding group pen ( $\left.\mathrm{SSI}_{\text {pen }}\right)$ measured at $2 \mathrm{~h}$ before the afternoon milking (h 9) and mean 24-h time spent standing in the stall for each of 12 herds. The relationship is explained by the equation $\mathrm{y}=17.3 \mathrm{x}-1.45 ; \mathrm{R}^{2}=0.91$. 
the afternoon milking) were tested further using multilinear regression analysis. The relationship between index and stall standing time at $2 \mathrm{~h}$ after the afternoon milking failed to remain significant, and at $5 \mathrm{~h}$ before the morning milking, the significant interaction between index and stall base type made interpretation of this relationship difficult across herds with either sand or mattress stall surfaces. However, CCI/ $\mathrm{SSI}_{\text {pen }}$ measured at $2 \mathrm{~h}$ before the morning or afternoon milking remained significant, in the absence of any interaction with stall base type, milking frequency, or number of rows of stalls in the pen. Although these time points were not the same as the optimal association between index and behavior at the cow level, they did have high adjusted $\mathrm{R}^{2}$ values and did trend toward significance in the cow level analysis. These differences between the pen level and cow level data may be explained by the large influence of a few cows' behavior on the magnitude of an index derived from only 10 cows, compared with an index derived from a pen of approximately 85 cows.

The indices of comfort used in this study do not appear to be sensitive indicators of cow comfort in terms of resting time as had previously been supposed. With the large number of repeated comparisons being made in this study, and the use of a Bonferroni-adjusted $P$ value to determine significance, it is possible that an association between an index of comfort and mean daily lying time was missed. The power of the study for finding such an association was low, and a larger sample size of around 25 herds would be required to completely rule out such an association. However, a significant

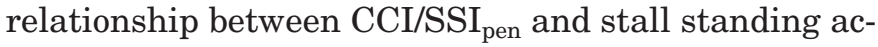
tivity was found, suggesting that this behavior was the dominant influence on the magnitude of the index.

Differences in stall standing activity have been associated with lameness and with different stall surfaces; and these differences are of relevance to the interpretation of the current data (Cook et al., 2004). The pen prevalence of clinical lameness was markedly higher in MAT herds than in SAND herds and increased time spent standing in the stall (in particular, perching in the stall) has been associated with an increased risk of lameness by several researchers (Colam-Ainsworth et al., 1989; Galindo et al., 2000). However, recent work using information derived from the data set used in the current study showed that stall standing activity varies with the locomotion score of the individual cow. Large increase in stall standing time above $2 \mathrm{~h} / \mathrm{d}$ were observed with increasing severity of lameness, but this change in behavior was only observed in lame cows in MAT herds, not in SAND herds (Cook et al., 2004). With a greater number of lame cows in MAT herds, it is possible that the indices of comfort were influenced by the behavior of the lame animals.

Measurement of CCI within $1 \mathrm{~h}$ of the return of the cows to the pen from the morning milking includes a group of cows that are able to use the stalls easily, early in their stall use session. Lying bouts typically last around 1 to $1.5 \mathrm{~h}$ (Cook et al., 2004; Tucker and Weary, 2004); therefore, for 2 to $3 \mathrm{~h}$ after return from the parlor and throughout the rest of the stay in the pen until the subsequent milking, comfort indices that assess whether a cow in a stall lying down or standing will be influenced by prolonged stall standing activity in lame cows. In SAND herds, lame cows have fewer long-duration standing bouts and spend significantly less time standing in the stall during a stall-use session, whereas in MAT herds, lame cows will stand in the stall for longer periods in excess of $2 \mathrm{~h} / \mathrm{d}$ (Cook et al., 2004). The more lame cows there are within a group in the MAT herds, the greater will be the proportion of the cows standing in the stall. Thus, when the CCI is measured at a time beyond the first lying bout during a pen stay, it is likely influenced by the stall standing activity of lame cows within the pen. Herds with high rates of clinical lameness and poorly designed free stalls with a mat or mattress surface will have lower values for CCI than will herds with lower rates of lameness and herds with deep-bedded, well-managed sand-filled stalls. Seemingly good stall use observed within $1 \mathrm{~h}$ of the return of the cows from milking may provide little information on stall use by lame and nonlame cows, and appears to be poorly related to lying behavior.

Recent work has shown that perching activity appears to be a cow response to difficulties using stalls of different designs and sizes. For example, Tucker et al., (2004) showed that perching was reduced in wider mattress stalls, which presumably made stall use easier. Neck rail location appeared to be particularly important in mattress stalls-neck rails that were closer to the rear curb resulted in increased periods of perching, and less time standing with all 4 feet on the stall platform (Tucker, 2003). The SPI pen $_{\text {index was not associated }}$ with mean resting time or with stall standing time, and perhaps surprisingly, it was higher in the SAND herds than in the MAT herds in the current study. This would appear to contradict the view held by others that perching is associated with lameness (Colam-Ainsworth et al., 1989; Galindo et al., 2000), as lameness prevalence was much lower in the SAND herds in this study. Clearly, neck-rail location is a major factor determining the type of stall standing activity (Tucker, 2003) and its correct location is problematic in deep, loose-bedded, sand-filled stalls, because cows do not seem to like standing with the rear feet on a sloped or rounded rear concrete curb (Cook et al., 2004). With neck rails located 
as they were in the SAND herds in this study (approximately $1.64 \mathrm{~m}$ from the rear curb and $1.19 \mathrm{~m}$ above the stall surface), cows would be forced to step back when standing, and perch in the stall. Thus, the greater perching activity observed in the SAND herds in this study may be a function of stall design and neck-rail placement. The fact that $\mathrm{SPI}_{\text {pen }}$ was not related to stall standing activity suggests that the factors driving perching and standing in stalls may be independent of each other, with perching being predominantly a function of stall design, and stall standing activity (which may include perching activity) being a function of lameness. Further work investigating the association between lameness and lesion type, perching activity, and stall design is required to fully explain why cows perch in free stalls.

\section{CONCLUSIONS}

This study failed to show a significant association between indices of cow comfort and mean 24-h lying time of the cows within the pen. However, CCI/SSI ${ }_{\text {pen }}$ was significantly associated with stall standing activity when captured $2 \mathrm{~h}$ before the morning or afternoon milkings. This activity has been shown to be a particular problem of lame cows in herds with poorly designed mattress stalls (Cook et al., 2004). For this reason, if an index of comfort is to be used, we prefer to use the term SSI, and to understand that it is representative of lame cow behavior. Prolonged herd mean daily stall standing times greater than $2 \mathrm{~h} / \mathrm{d}$ are associated with an SSI greater than 0.20 , measured $2 \mathrm{~h}$ before the morning or afternoon milking. A one-time measurement of more than $20 \%$ of the cows standing in stalls $2 \mathrm{~h}$ before the morning or afternoon milking would suggest that a more thorough investigation of herd lameness prevalence and associated risk factors, including free-stall design evaluation, is required.

\section{ACKNOWLEDGMENTS}

The authors acknowledge and appreciate the assistance of Murray Clayton, College of Agriculture and Life Sciences, University of Wisconsin, with the statistical analysis, and Rebecca Krull with the video analysis. The work was funded by the UW-SVM Food Animal
Fund, a donation from Land O'Lakes, Inc., and other supporters of the UW Cow Comfort and Well-Being Consortium, including Zinpro Corporation, Pfizer Animal Health, Vita Plus Corporation, and L and L Sales and Service, Inc.

\section{REFERENCES}

Colam-Ainsworth, P., G. A. Lunn, R. C. Thomas, and R. G. Eddy. 1989. Behaviour of cows in cubicles and its possible relationship with laminitis in replacement dairy heifers. Vet. Rec. 125:573575.

Cook, N. B. 2002. The influence of barn design on dairy cow hygiene, lameness, and udder health. Pages 97-103 in Proc. 35th Annu. Conf. Am. Assoc. Bovine Pract., Madison, WI. AABP, Rome, GA.

Cook, N. B. 2003. Prevalence of lameness among dairy cattle in Wisconsin as a function of housing type and stall surface. JAVMA 223:1324-1328.

Cook, N. B., T. B. Bennett, and K. V. Nordlund. 2004. Effect of free stall surface on daily activity patterns in dairy cows with relevance to lameness prevalence. J. Dairy Sci. 87:2912-2922.

DeVries, T. J., and M. A. G. von Keyserlingk. 2005. Time of feed delivery affects the feeding and lying patterns of dairy cows. J. Dairy Sci. 88:625-631.

Dohoo, I., W. Martin, and H. Stryhn. 2003. Page 202 in Veterinary Epidemiologic Research. AVC Inc., Charlottetown, Prince Edward Island, Canada.

Galindo, F., D. M. Broom, and P. G. G. Jackson. 2000. A note on possible link between behaviour and the occurrence of lameness in dairy cows. Appl. Anim. Behav. Sci. 67:335-341.

Metz, J. H. M. 1985. The reaction of cows to a short-term deprivation of lying. Appl. Anim. Behav. Sci. 13:301-307.

Miller, K., and D. G. M. Wood-Gush. 1991. Some effects of housing on the social behavior of dairy cows. Anim. Prod. 53:271-278.

Nelson, A. J. 1996. On-farm nutrition diagnostics. Pages 76-85 in Proc. 29th Annu. Conf. Am. Bovine Pract., San Diego, CA. AABP, Rome, GA.

Overton, M. W., D. A. Moore, and W. M. Sischo. 2003. Comparison of commonly used indices to evaluate dairy cattle lying behavior. Pages 125-130 in Proc. 5th Intl. Dairy Housing Conf., Fort Worth, TX. ASAE, St. Joseph, MI.

Overton, M. W., W. M. Sischo, G. D. Temple, and D. A. Moore. 2002. Using time-lapse video photography to assess dairy cattle lying behavior in a free-stall barn. J. Dairy Sci. 85:2407-2413.

SAS Institute. 1999. SAS/STAT User's Guide. Version 8. SAS Inst., Inc., Cary, NC.

Tucker, C. B. 2003. The effects of free stall surfaces and geometry on dairy cattle behavior. Ph.D. Thesis. The University of British Columbia, BC, Canada.

Tucker, C. B., and D. M. Weary. 2004. Bedding on geotextile mattresses: How much is needed to improve cow comfort? J. Dairy Sci. 87:2889-2895.

Tucker, C. B., D. M. Weary, and D. Fraser. 2003. Effects of three types of free-stall surfaces on preferences and stall usage by dairy cows. J. Dairy Sci. 86:521-529.

Tucker, C. B., D. M. Weary, and D. Fraser. 2004. Free-stall dimensions: Effects on preference and stall usage. J. Dairy Sci. $87: 1208-1216$. 